\title{
Oxidation Performance of Ytterbium Disilicate/Silicon Environmental Barrier Coating via Optimized Air Plasma Spraying
}

\author{
Yingjie Jian, Yanfei Wang*, Rongjun Liu, Fan Wan \\ Science and Technology on Advanced Ceramic Fibers and Composites Laboratory, National University of Defense Technology, \\ Changsha, China \\ Email: jianyingjie7788@163.com, *wangyanfei@nudt.edu.cn, rongjunliu@163.com,wanfan19900605@hotmail.com
}

How to cite this paper: Jian, Y.J., Wang, Y.F., Liu, R.J. and Wan, F. (2021) Oxidation Performance of Ytterbium Disilicate/ Silicon Environmental Barrier Coating via Optimized Air Plasma Spraying. Journal of Materials Science and Chemical Engineering, 9, 19-26.

https://doi.org/10.4236/msce.2021.94003

Received: March 16, 2021

Accepted: April 10, 2021

Published: April 13, 2021

\begin{abstract}
Environmental barrier coatings (EBCs) play a critical role in mitigating the degradation of $\mathrm{SiC}_{\mathrm{f}} / \mathrm{SiC}$ ceramic matrix composites (CMCs) in complex combustion environment, and improve the service life of thermal engine components. In this paper, by adjusting the parameters of atmospheric plasma spraying (APS), the spraying process of ytterbium disilicate $\left(\mathrm{Yb}_{2} \mathrm{Si}_{2} \mathrm{O}_{7}\right)$ under a lower power has been optimized. A two-layer EBC system consisting of ytterbium disilicate and silicon is prepared on the $\mathrm{SiC}_{\mathrm{f}} / \mathrm{SiC}$ composite substrate by using optimized technological parameters. The thermal resistance and water oxygen corrosion resistance of such two-layer EBC system are investigated. The results indicate that the current ytterbium disilicate/silicon EBC system exhibits good phase stability, excellent water vapor and oxygen corrosion resistance. However, the exposed silicon bonding layer tends to generate an excessive thermal growth oxide (TGO) layer known as $\mathrm{SiO}_{2}$, leading to an early spallation of the coating.
\end{abstract}

\section{Keywords}

Environmental Barrier Coating, Air Plasma Spraying, Ytterbium Disilicate, $\mathrm{SiC}_{\mathrm{f}} / \mathrm{SiC}$ Composites

\section{Introduction}

The improvement of thrust-to-weight ratio of advanced aero-engines is highly dependent on the development and application of advanced materials. To improve the thrust-to-weight ratio, gas turbine's inlet temperature has to be increased, which severely challenges hot-section components. Thanks to thermal 
barrier coatings and sophisticated cooling technology, nickel-based superalloys can tackle current temperature challenges, but are not capable of satisfying future development of continuous increase of service temperature. Instead, silicon carbide fiber reinforced silicon carbide ceramic matrix composites $\left(\mathrm{SiC}_{\mathrm{f}} / \mathrm{SiC}-\mathrm{CMCs}\right)$ are proposed as an ideal material for engine components such as regulating piece, seal, heat insulation screen and turbine blades etc. due to their high melting point, low density, good thermo-mechanical properties and anti-oxidation properties [1] [2] [3]. However, while considering the high temperature combustion environments with high humidity, the dense film of $\mathrm{SiO}_{2}$ on the surface of $\mathrm{SiC}_{\mathrm{f}} / \mathrm{SiC}$ composites tends to react with water vapor to form volatile products, leading to the rapid degradation of $\mathrm{SiC}_{\mathrm{f}} / \mathrm{SiC}$ composites [4] [5]. Therefore, it is necessary to deposit environmental barrier coatings (EBCs) on the surface of $\mathrm{SiC}_{\mathrm{f}} / \mathrm{SiC}$ composite components to physically isolate components from the complex engine environment and ultimately extend the service life of the CMC components [6] [7].

NASA [8] [9] is leading the research on EBCs, and the research in China has made great progress in these years. It can be divided into four stages for EBC systems. Currently, researchers mainly focus on rare earth silicate systems [10] and move towards material systems of multi-layered thermal barrier coupled with environmental barrier [11]. The main preparation methods of EBCs include air plasma spraying [12] (APS), electron beam physical vapor deposition [13] (EB-PVD), plasma spraying physical vapor deposition [14] (PS-PVD), ultra-low pressure plasma spraying [15] (VLPPS), etc. APS technology has been widely used as the preparation of EBCs because of its simple operation, high efficiency and low cost. But in the process of spraying, there are inevitably unmelt powder existed in rare earth silicate coatings. Hence, it is difficult to form a coating with very high density [16]. Meanwhile, high spraying power leads to the volatilization of Si causing the deviation of coating composition. Further, the slight oxidation occurs on silicon bond coat during the spraying process [17].

In this paper, an $\mathrm{Yb}_{2} \mathrm{Si}_{2} \mathrm{O}_{7} / \mathrm{Si} \mathrm{EBC}$ prepared by APS is investigated. After optimization of APS parameters, the microstructure, phase composition, thermal stability and water vapor corrosion resistance of this EBCs system were characterized.

\section{Experiment}

\subsection{Sample Preparation}

The $\mathrm{SiC}_{\mathrm{f}} / \mathrm{SiC}$ substrates were prepared by a hybrid route combining chemical vapor infiltration (CVI) and precursor infiltration and pyrolysis (PIP) techniques. The substrates were polished, cleaned and dried before APS, without sandblasting treatment. The raw materials of $\mathrm{Yb}_{2} \mathrm{Si}_{2} \mathrm{O}_{7}$ powders were commercially available (Beijing Sandspray New Material Co., Ltd.). To ensure the fluidity of the powder, the powders were subjected to a spray pelletization process. The silicon powders with particle size between 50 - $70 \mu \mathrm{m}$ were purchased from 
Metco with a brand of 4810. A low-power APS with different current level was used to prepare $\mathrm{Yb}_{2} \mathrm{Si}_{2} \mathrm{O}_{7}$ topcoat while $\mathrm{Si}$ bond coat was employed by another set of parameters. All parameters are listed in Table 1.

\subsection{Characterization}

Thermal treatment in air as well as in water vapor and oxygen corrosion of the bi-layer EBCs are investigated. The thermal treatments were under $1300^{\circ} \mathrm{C}$, $1400^{\circ} \mathrm{C}$, and $1500^{\circ} \mathrm{C}$ respectively for 10 hours; the water vapor and oxygen corrosion test was carried out at $1300^{\circ} \mathrm{C}$ in an alumina tube furnace, where the volume ratio of oxygen to water vapor was kept as 1:1. The test was carried out in a cycle of $20 \mathrm{~h}$, and samples were taken out every 2 cycles for characterization. Scanning electron microscope (SEM, MIRA3, Tescan, China) was used to observe the surface and cross-section morphology of the coatings. Energy dispersive spectrometer (EDS, $\mathrm{x}$-max20, Oxford Instrument, UK) was used to measure element distribution. The image analysis software (ImagJ) was used to perform the threshold segmentation of the images. The specific method was to partition the samples and select 5 images evenly, where the resolution of the images and the width of the field of view were consistent. XRD (D8-advance, Bruker, $0.02^{\circ} /$ step, $\mathrm{Cu}-\mathrm{K} \alpha, 10^{\circ}-90^{\circ}$ ) analysis was carried out to investigate the phase composition of the coating under various treatments.

\section{Result and Discussion}

\subsection{Optimization of Spraying Parameters}

Figure 1 shows the SEM images of cross-section morphology of $\mathrm{Yb}_{2} \mathrm{Si}_{2} \mathrm{O}_{7}$ coatings prepared by three different parameters of low power. The topcoat is dense

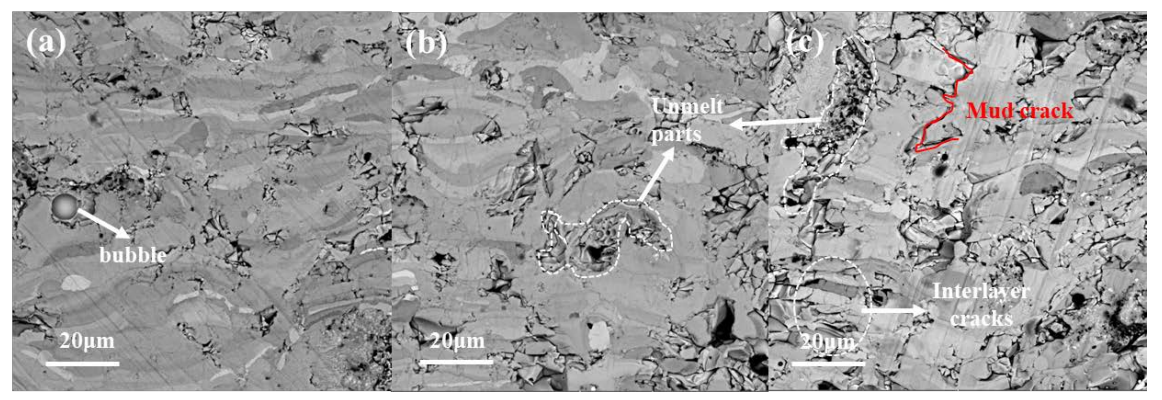

Figure 1. Cross-sectional morphologies of $\mathrm{Yb}_{2} \mathrm{Si}_{2} \mathrm{O}_{7}$ topcoats. (a) parameter 2; (b) parameter 3; (c) parameter 4 .

Table 1. Air plasma spraying parameters for $\mathrm{Si}$ and $\mathrm{Yb}_{2} \mathrm{Si}_{2} \mathrm{O}_{7}$ coatings.

\begin{tabular}{cccccc}
\hline & Material & Current (A) & $\mathrm{Ar}(\mathrm{slm})$ & $\mathrm{H}_{2}(\mathrm{slm})$ & Power $(\mathrm{kW})$ \\
\hline Parameter 1 & $\mathrm{Si}$ & 500 & 70 & 1 & 30.0 \\
Parameter 2 & $\mathrm{Yb}_{2} \mathrm{Si}_{2} \mathrm{O}_{7}$ & 300 & 45 & 2 & 18.0 \\
Parameter 3 & $\mathrm{Yb}_{2} \mathrm{Si}_{2} \mathrm{O}_{7}$ & 350 & 45 & 2 & 19.3 \\
Parameter 4 & $\mathrm{Yb}_{2} \mathrm{Si}_{2} \mathrm{O}_{7}$ & 400 & 45 & 2 & 22.0 \\
\hline
\end{tabular}


on the whole with a morphology of multi-layer stacking, and the defects in the topcoat are mainly spherical pores and interlayer cracks. The average porosity measured by image method are $11.5 \%, 8.1 \%$ and $10.0 \%$, respectively. The change of grayscale of the photo is mainly caused by the loss of $\mathrm{Si}$. The more Si loss is, the higher the brightness of the area will be. It is difficult to characterize the exact $\mathrm{Si}$ loss and the corresponding phase composition of the image. But it can be observed in Figure 1 that the brightness region of the coating increases with the increase of power.

In the Parameter 4, interlayer cracks and mud cracks obviously increased, and the reason can be summed up in the increasing of $\mathrm{Yb}_{2} \mathrm{SiO}_{5}$ or even $\mathrm{Yb}_{2} \mathrm{O}_{3}$. As the high melt point of the two phases $\left(\mathrm{Yb}_{2} \mathrm{SiO}_{5}\right.$ for $1950^{\circ} \mathrm{C}, \mathrm{Yb}_{2} \mathrm{O}_{3}$ for $\left.2415^{\circ} \mathrm{C}\right)$, the molten particles in the spraying process are not able to make the previous layer melt, leading to an obvious interlayer interface. When the particles are rapidly cooling in the substrate, lamella contraction occurs with the release of the thermal stress, which results in the growth of micro cracks. Comparing to the cross-section morphologies of parameter 2 and parameter 3 , the areas of pores, cracks and unmelt particle areas are greatly reduced, although there are still some remained.

Figure 2(a) shows the XRD patterns of the topcoats prepared by different three parameters at $1300^{\circ} \mathrm{C}$. And the XRD patterns of the raw powder, the as-sprayed topcoats and the topcoats after annealing are shown in Figure 2(b). After thermal treatment at $1300^{\circ} \mathrm{C}$, the coatings in three parameters transform into a highly crystalline state, and the main phase composition is $\mathrm{Yb}_{2} \mathrm{Si}_{2} \mathrm{O}_{7}$ and $\mathrm{Yb}_{2} \mathrm{SiO}_{5}$. The phase content does not change significantly with the change of parameters. The other XRD pattern indicates that the as-sprayed coatings are amorphous, and the phase composition of raw powder and the annealed topcoat are nearly the same. These two patterns all suggest that the phase change in the spraying process is slight due to the selection of low power parameters.

Based on the calculation results of porosity, cross-section morphologies and phase evolutions, it can be concluded that parameter 3 is an optimal spraying parameter for APS and the low power is necessary to keep the original phase
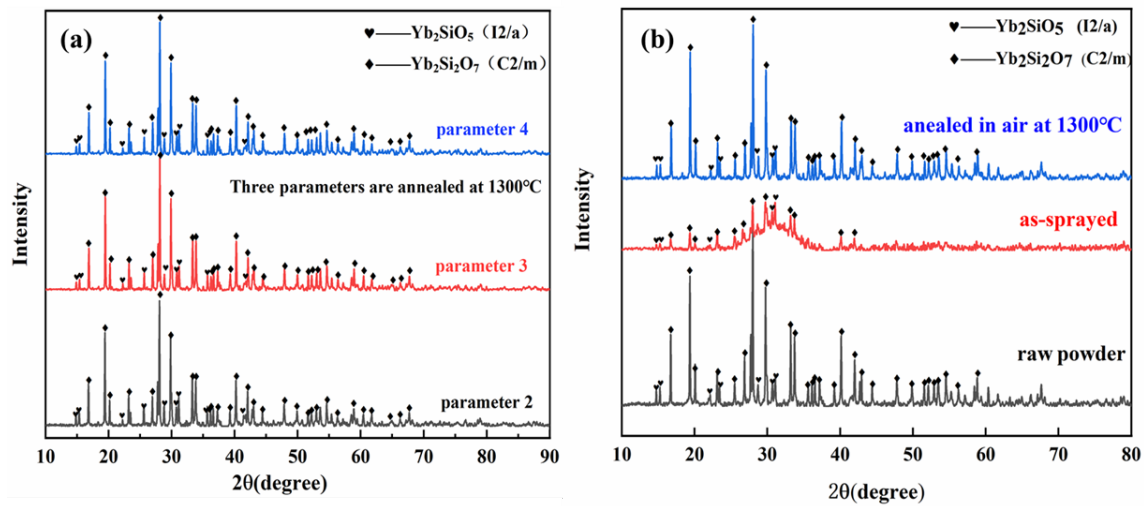

Figure 2. XRD patterns of (a) different parameters prepared at $1300^{\circ} \mathrm{C}$; (b) the raw powder, the as-sprayed topcoats and the topcoats after annealing. 
composition. Then thermal treatment and water oxygen corrosions will be performed using optimized parameter 3 .

\subsection{Thermal Stability}

XRD patterns of $\mathrm{Yb}_{2} \mathrm{Si}_{2} \mathrm{O}_{7}$ topcoats with parameter 3 after thermal treatment at $1300^{\circ} \mathrm{C}-1500^{\circ} \mathrm{C}$ are shown in Figure 3(a), which is corresponding to the surface morphologies in Figures 3(b)-(d) separately. The XRD patterns show that with the increasing of annealing temperature, the phase composition is stable, consisting of $\mathrm{Yb}_{2} \mathrm{Si}_{2} \mathrm{O}_{7}$ and little $\mathrm{Yb}_{2} \mathrm{SiO}_{5}$, and the intensity of $\mathrm{Yb}_{2} \mathrm{SiO}_{5}$ phase is reduced. There is no evidence that any reaction was taken in the isolate thermal treatment in air [18]. According to the microstructure, it can be inferred that the rapid grain growing may bring some influence on the XRD detecting. The surface morphologies show that the surface layers are not in dense stacks, and there are pores remained and microcracks occurred due to the thermal stress.

\subsection{Water Vapor and Oxidation Resistance}

The overall structure is shown in Figure 4(a) and Figure 4(b). The system is clearly divided into three layers which are well bonded. There are no obvious cracks or declination. For as-sprayed $\mathrm{Yb}_{2} \mathrm{Si}_{2} \mathrm{O}_{7}$ topcoat, the morphology of crosssection is quite different from the corroded sample for $120 \mathrm{~h}$, which changes from layered rough state to dense smooth state after corrosion. Meanwhile, the phase distribution changed from unobvious to obvious dark and bright two-phase distribution. The topcoat along with the bond coat provides oxidation resistance for $\mathrm{SiC}_{\mathrm{f}} / \mathrm{SiC}$ composites, and there is slight oxidation due to the diffusion of oxygen. As the Figure 4(c) and Figure 4(d) shown, the interface between $\mathrm{Yb}_{2} \mathrm{Si}_{2} \mathrm{O}_{7}$ topcoats and $\mathrm{Si}$ bond coat combines well as sprayed, and forms a $\mathrm{SiO}_{2}$
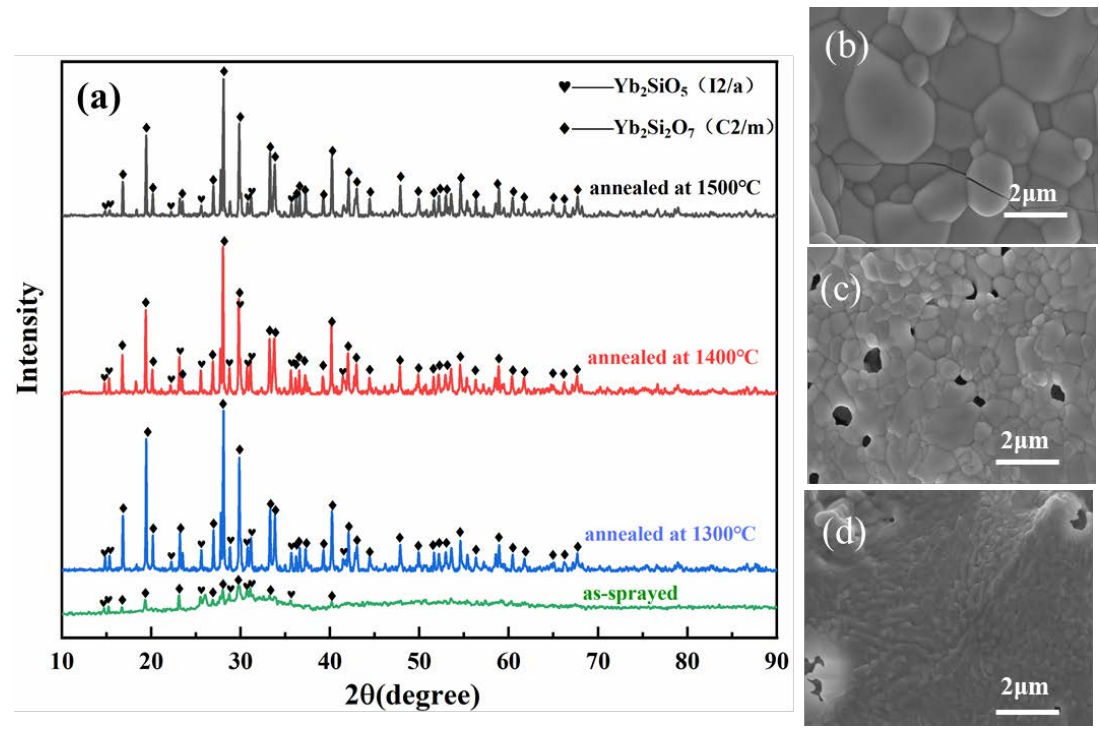

Figure 3. (a) XRD patterns of $\mathrm{Yb}_{2} \mathrm{Si}_{2} \mathrm{O}_{7}$ topcoats deposited using plasma spray parameter 3 which were separately annealed at $1300^{\circ} \mathrm{C}, 1400^{\circ} \mathrm{C}, 1500^{\circ} \mathrm{C}$ for $10 \mathrm{~h}$; Surface morphologies at (b) $1500^{\circ} \mathrm{C}$; (c) $1400^{\circ} \mathrm{C}$; (d) $1300^{\circ} \mathrm{C}$. 

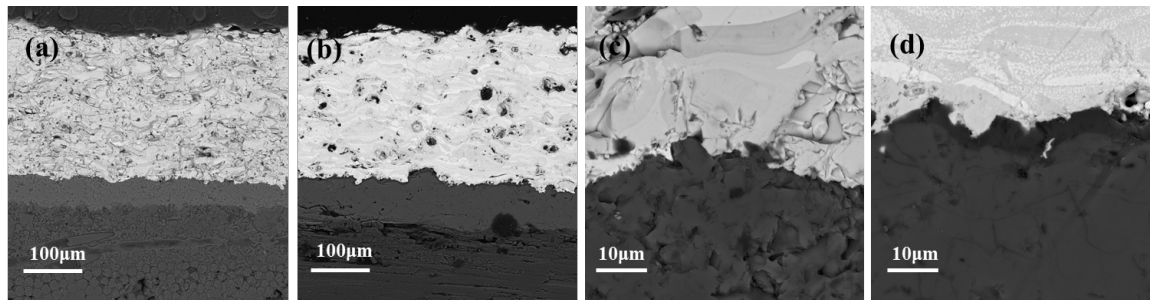

Figure 4. Cross-sectional SEM photos of EBC (a) as-sprayed; (b) corrosion for $160 \mathrm{~h}$; Interfaces between $\mathrm{Yb}_{2} \mathrm{Si}_{2} \mathrm{O}_{7}$ topcoat and $\mathrm{Si}$ bond coat (c) as-sprayed; (d) corrosion for $160 \mathrm{~h}$ at $1300^{\circ} \mathrm{C}$.
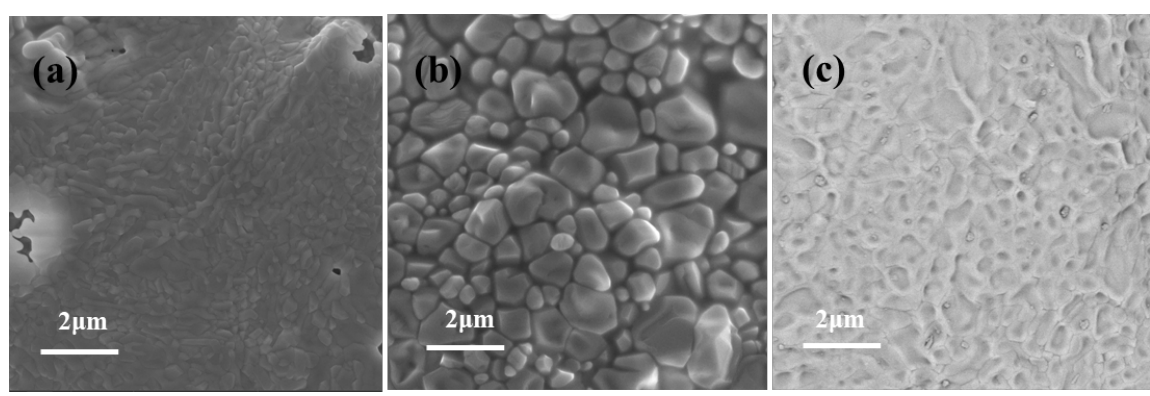

Figure 5. Surface of $\mathrm{Yb}_{2} \mathrm{Si}_{2} \mathrm{O}_{7}$ topcoats (a) annealed in $1300^{\circ} \mathrm{C}$; (b), (c) different areas corroded for $160 \mathrm{~h}$.

layer called thermal growth oxide (TGO) after corrosion for $160 \mathrm{~h}$. The TGO is a critical cause for the decline of EBC system, due to its special phase transition and volume change at $220^{\circ} \mathrm{C}$. When the $\mathrm{Si}$ or $\mathrm{SiC}$ is exposed to the corrosion environment, the excessive formation of TGO will face great stress and rapid volatilization resulting in the failure of the EBC system [19].

Figure 5 shows the microstructure on the surface of $\mathrm{Yb}_{2} \mathrm{Si}_{2} \mathrm{O}_{7}$ topcoats. After corrosion for $160 \mathrm{~h}$, the grain boundary is corroded, but in other areas, the topcoat was protected by a new, dense material. According to the EDS analyzation, the new material is rich of $\mathrm{Al}$, which is mentioned to have the reactions as following:

$$
3 \mathrm{Yb}_{2} \mathrm{Si}_{2} \mathrm{O}_{7}(\mathrm{~s})+10 \mathrm{Al}(\mathrm{OH})_{3}(\mathrm{~g}) \rightarrow 2 \mathrm{Yb}_{3} \mathrm{Al}_{5} \mathrm{O}_{12}(\mathrm{~s})+6 \mathrm{Si}(\mathrm{OH})_{4}(\mathrm{~g})+3 \mathrm{H}_{2} \mathrm{O}(\mathrm{g})
$$

The product has even better resistance compared to other rare earth silicates [20].

Though, it is difficult to avoid the spraying defects in the EBC, which weakens the mechanical properties of the coatings. The effects of EBC systems for protecting $\mathrm{SiC}_{\mathrm{f}} / \mathrm{SiC}$ composites from oxidation and corrosion are proved to be indeed excellent.

\section{Conclusions}

The APS parameters are optimized in the low power level. The bi-layer EBC prepared by the optimized process underwent a thermal treatment as well as a water vapor and oxygen corrosion at $1300^{\circ} \mathrm{C}$. The results can be summarized as following: 
1) Low power in APS is needed for less phase change taking place in the process. And parameter 3 is convinced to be the better one due to its fewer pores and better morphology.

2) Oxidation is mainly taken place between the $\mathrm{Yb}_{2} \mathrm{Si}_{2} \mathrm{O}_{7}$ topcoats and $\mathrm{Si}$ bond coat. Corrosion occurs on the surface of $\mathrm{Yb}_{2} \mathrm{Si}_{2} \mathrm{O}_{7}$ topcoats, and $\mathrm{Yb}_{3} \mathrm{Al}_{5} \mathrm{O}_{12}$ makes a contribution to the oxidation resistance. The bi-layer $\mathrm{Yb}_{2} \mathrm{Si}_{2} \mathrm{O}_{7} / \mathrm{Si} \mathrm{EBC}$ system is eventually convinced to be an excellent choice for future gas engine components.

\section{Conflicts of Interest}

The authors declare no conflicts of interest regarding the publication of this paper.

\section{References}

[1] Padture, N.P. (2016) Advanced Structural Ceramics in Aerospace Propulsion, NAT. MATER, 15, 804-809. https://doi.org/10.1038/nmat4687

[2] Patra, N., Nasiri, N.A., Ni, N., Jayaseelan, D.D. and Lee, W.E. (2016) Oxidation Behaviour of SiC/SiC Ceramic Matrix Composites in Air. J. EUR. CERAM. SOC., 36. https://doi.org/10.1016/j.jeurceramsoc.2016.05.051

[3] Yamada, R., Taguchi, T. and Igawa, N. (2000) Mechanical and Thermal Properties of 2D and 3D SiC/SiC Composites. J. NUCL. MATER, 283-287, 574-578. https://doi.org/10.1016/S0022-3115(00)00144-6

[4] Eaton, H.E. and Linsey, G.D. (2002) Accelerated Oxidation of SiC CMC's by Water Vapor and Protection via Environmental Barrier Coating Approach. J. EUR. CERAM. SOC., 22, 2741-2747. https://doi.org/10.1016/S0955-2219(02)00141-3

[5] Zok, F.W., Maxwell, P.T., Kawanishi, K. and Callaway, E.B. (2019) Degradation of a SiC-SiC Composite in Water Vapor Environments. J. AM. CERAM. SOC., 103, 1927-1941. https://doi.org/10.1111/jace.16838

[6] Lee, K.N. (2000) Current Status of Environmental Barrier Coatings for Si-Based Ceramics. SURF. COAT. TECH., 133, 1-7. https://doi.org/10.1016/S0257-8972(00)00889-6

[7] Tejero-Martin, D., Bennett, C. and Hussain, T. (2021) A Review on Environmental Barrier Coatings: History, Current State of the Art and Future Developments. J. EUR. CERAM. SOC., 41, 1747-1768. https://doi.org/10.1016/j.jeurceramsoc.2020.10.057

[8] Lee, K.N., Fox, D.S., Eldridge, J.I., Bansal, N.P., Miller, R.A., Zhu, D. and Robinson, R.C. (2003) Upper Temperature Limit of Environmental Barrier Coatings Based on Mullite and BSAS. Symposium on Water Vapor Effects on Oxidation of HighTemperature. https://doi.org/10.1111/j.1151-2916.2003.tb03466.x

[9] Bradley, T. (2015) Mechanisms of Ytterbium Monosilicate/Mullite/Silicon Coating Failure during Thermal Cycling in Water Vapor. J. AM. CERAM. SOC.

[10] Tian, Z., Ren, X., Lei, Y., Zheng, L., Geng, W., Zhang, J. and Wang, J. (2019) Corrosion of $\mathrm{RE}_{2} \mathrm{Si}_{2} \mathrm{O}_{7}(\mathrm{RE}=\mathrm{Y}, \mathrm{Yb}$, and $\mathrm{Lu})$ Environmental Barrier Coating Materials by Molten Calcium-Magnesium-Alumino-Silicate Glass at High Temperatures. J. EUR. CERAM. SOC., 39, 4245-4254. https://doi.org/10.1016/j.jeurceramsoc.2019.05.036

[11] Turcer, L.R. and Padture, N.P. (2018) Towards Multifunctional Thermal Environmental Barrier Coatings (TEBCs) Based on Rare-Earth Pyrosilicate Solid-Solution 
Ceramics. SCRIPTA MATER, 154, 111-117.

https://doi.org/10.1016/j.scriptamat.2018.05.032

[12] Richards, B.T. and Wadley, H.N.G. (2014) Plasma Spray Deposition of Tri-Layer Environmental Barrier Coatings. J. EUR. CERAM. SOC., 34, 3069-3083.

https://doi.org/10.1016/j.jeurceramsoc.2014.04.027

[13] Zimmermann, B. (2017) The Potential of Plasma Activation for EB-PVD of EBC Systems on CMC Components. Advanced Ceramic Matrix Composites: Science and Technology of Materials, Design, Applications, Performance and Integration Conference.

[14] Zhang, X., Song, J., Deng, Z., Wang, C., Niu, S., Liu, G., Deng, C., Deng, C., Liu, M., Zhou, K. and Lu, J. (2020) Interface Evolution of Si/Mullite/ $\mathrm{Yb}_{2} \mathrm{SiO}_{5}$ PS-PVD Environmental Barrier Coatings under High Temperature. J. EUR. CERAM. SOC., 40, 1478-1487. https://doi.org/10.1016/j.jeurceramsoc.2019.10.062

[15] Bakan, E., Marcano, D., Zhou, D., Sohn, Y.J., Mauer, G. and Vaßen, R. (2017) $\mathrm{Yb}_{2} \mathrm{Si}_{2} \mathrm{O}_{7}$ Environmental Barrier Coatings Deposited by Various Thermal Spray Techniques: A Preliminary Comparative Study. J. THERM. SPRAY TECHN., 26, 1011-1024. https://doi.org/10.1007/s11666-017-0574-1

[16] Richards, B.T., Zhao, H. and Wadley, H.N.G. (2015) Structure, Composition, and Defect Control during Plasma Spray Deposition of Ytterbium Silicate Coatings. J. MATER. SCI., 50, 7939-7957. https://doi.org/10.1007/s10853-015-9358-5

[17] Arai, Y., Aoki, Y. and Kagawa, Y. (2017) Effect of Cristobalite Formation on the Delamination Resistance of an Oxide/Si/(SiC/SiC) Environmental Barrier Coating System after Cyclic High Temperature Thermal Exposure. SCRIPTA MATER, 139, 58-62. https://doi.org/10.1016/j.scriptamat.2017.06.006

[18] Zhong, X., Niu, Y., Li, H., Zhu, T., Song, X., Zeng, Y., Zheng, X., Ding, C. and Sun, J. (2018) Comparative Study on High-Temperature Performance and Thermal Shock Behavior of Plasma-Sprayed $\mathrm{Yb}_{2} \mathrm{SiO}_{5}$ and $\mathrm{Yb}_{2} \mathrm{Si}_{2} \mathrm{O}_{7}$ Coatings. Surface and Coatings Technology, 349. 636-646. https://doi.org/10.1016/j.surfcoat.2018.06.056

[19] Richards, B.T., Young, K.A., de Francqueville, F., Sehr, S., Begley, M.R. and Wadley, H.N.G. (2016) Response of Ytterbium Disilicate-Silicon Environmental Barrier Coatings to Thermal Cycling in Water Vapor. ACTA MATER, 106, 1-14. https://doi.org/10.1016/j.actamat.2015.12.053

[20] Maier, N., Nickel, K.G. and Rixecker, G. (2007) High Temperature Water Vapour Corrosion of Rare Earth Disilicates $(\mathrm{Y}, \mathrm{Yb}, \mathrm{Lu})_{2} \mathrm{Si}_{2} \mathrm{O}_{7}$ in the Presence of $\mathrm{Al}(\mathrm{OH})_{3}$ Impurities. J. EUR. CERAM. SOC., 27, 2705-2713.

https://doi.org/10.1016/j.jeurceramsoc.2006.09.013 